\title{
Impact of nutritional status on outcome of pancreatic resections for pancreatic cancer and periampullary tumors
}

\author{
Vittorio Grazio Perrone ${ }^{1}$, Sara Iacopi ${ }^{1}$, Gabriella Amorese ${ }^{2}$, Ugo Boggi ${ }^{1}$ \\ ${ }^{1}$ Division of General and Transplant Surgery, University of Pisa, Pisa, Italy; ${ }^{2}$ Division of Anesthesia and Intensive Care, Azienda Ospedialiero- \\ Universitaria Pisana, Pisa, Italy \\ Correspondence to: Ugo Boggi. Division of General and Transplant Surgery, University of Pisa, Via Paradisa 2, 56124, Pisa, Italy. \\ Email: u.boggi@med.unipi.it. \\ Comment on: Seika P, Klein F, Pelzer U, et al. Influence of the body mass index on postoperative outcome and long-term survival after pancreatic \\ resections in patients with underlying malignancy. Hepatobiliary Surg Nutr 2019;8:201-10.
}

Submitted May 19, 2020. Accepted for publication Jun 02, 2020.

doi: 10.21037/hbsn-20-498

View this article at: http://dx.doi.org/10.21037/hbsn-20-498

The high complication rate of pancreatic resections and the poor oncologic outcome of pancreatic and periampullary malignancies cannot be explained by just a single factor. There are, however, some underlying elements that affect both surgical outcomes and cancer prognosis. Nutritional status and nutritional support/therapy are among these factors, as they strongly impact on both surgical recovery (1) and cancer survival (2). Additionally, pancreatic cancer entails specific nutritional and metabolic derangements (3) that can lead to immunological deterioration and further enhance tumor aggressiveness (4). Approximately $66 \%$ of the patients with pancreas cancer are malnourished (5). Nutritional assessment, support, and therapy are all recommended in pancreatic surgery (1).

In a recent article Seika and coworkers reported on the outcome of 1,384 open pancreatoduonectomies for pancreatic and periampullary cancer. Results were reported based on patients' body mass index (BMI). BMI was found to predict early outcome and long-term survival. In detail, obesity (BMI $>30.0 \mathrm{~kg} / \mathrm{m}^{2}$ ) was associated with increased frequency of post-pancreatectomy hemorrhage, postoperative pancreatic fistula (POPF), bile leakage, wound infection, SIRS/sepsis, and need for reoperation. Underweight (BMI $<18.5 \mathrm{~kg} / \mathrm{m}^{2}$ ), on the other hand, was shown to have higher 30- and 90-day mortality and inferior long-term survival, despite lower incidence of post-operative complications and similar histopathology parameters (6). Higher mortality in underweight patients, despite lower incidence of postoperative complications, means high failure to rescue. Failure to rescue is a relatively new quality metric indicating the proportion of patients who are not rescued following potentially treatable complications (7). In the context of uniform postoperative management policy, higher failure to rescue clearly demonstrates the frailty of underweight patients.

BMI is recommended by the World Health Organization to assess nutritional status, mainly in the assumption that it defines the excess of fat storage. In adults, a $\mathrm{BMI}<18.5 \mathrm{~kg} / \mathrm{m}^{2}$ corresponds to underweight, a BMI $\geq 25 \mathrm{~kg} / \mathrm{m}^{2}$ to overweight, and a BMI $\geq 30 \mathrm{~kg} / \mathrm{m}^{2}$ to obesity (8). BMI, however, can miss important nutritional conditions, such as sarcopenia, thus providing only a rough picture of nutritional status.

Underweight, in cancer patients, is associated with low performance status (5), and often means cachexia. Cachexia is a complex syndrome, including weight loss, marked by muscle wasting, increased muscle protein catabolism, insulin resistance and inflammation (5). Cachexia was associated with poor outcome after pancreatoduodenectomy (9).

Obesity, at the other extreme of BMI spectrum, is also a complex syndrome characterized by type 2 diabetes, coronary artery disease, hypertension, dyslipidemia, non-alcoholic fatty liver disease, and increased risk for development of several cancers (10). Actually, some patients may be metabolically obese despite normal weight making metabolic profile potentially more relevant than BMI in defining the risks associated with obesity. Patients who are metabolically obese, despite normal weight phenotype, show 
most of the negative medical features of obesity such as high cardiovascular risk profile, high proportion of visceral fat, low insulin sensitivity, hyperinsulinemia, dyslipidemia and high plasma level of proinflammatory cytokines (11). From the specific point of view of the pancreatic surgeon, high BMI correlates with fatty infiltration of the pancreas which, in turn, is associated with higher rates of POPF (12). Additionally, visceral obesity can make the procedure more technically demanding.

In 2015 approximately $39 \%$ of the world's adult population was either overweight (1.9 billion persons) or obese (609 million persons), with a generally higher prevalence in women and an age-related increase peaking between the ages of 50 to 65 years. By the year 2030 approximately $58 \%$ of the world population is anticipated to be overweight or obese (13). At the same time, pancreatic cancer is estimated to become the second leading cause of cancer-related mortality (14). Considering that a high BMI is associated with increased risk of pancreatic cancer (15) in the next years patients with pancreatic cancer are expected to be frequently obese.

When making an overall assessment on the impact of obesity on the outcome of pancreatic resections, despite conflicting data (9) the global picture shows that obesity increases surgical risk especially concerning POPF (12). A minimally invasive approach could mitigate the impact of obesity on the outcome of pancreatic resections but, unfortunately, just few studies have investigated this key issue.

Girgis and coworkers reported the outcome of 474 pancreatoduodenectomies, including 213 robotic pancreatoduodenectomies and 145 procedures performed in obese patients. Compared to non-obese patients, obese patients showed a higher estimated blood loss (EBL), a higher rate of clinically relevant POPF, and a higher rate of wound infections. In the obese group 75 patients underwent open pancreatoduodenectomy and 70 robotic pancreatoduodenectomy. Despite similar baseline characteristics, robotic pancreatoduodenectomy was associated with shorter operating room time (381 vs. 428 minutes; $\mathrm{P}=0.003)$, lower $\mathrm{EBL}$ (250 vs. $500 \mathrm{~mL}$, $\mathrm{P}=0.001)$, a reduced need for red blood cell (RBC) transfusions $(17 \%$ vs. $33 \%, \mathrm{P}=0.035)$, a lower rate of clinically relevant $\mathrm{POPF}$, and a decreased incidence of wound infection ( $19 \%$ vs. $44 \%, \mathrm{P}=0.001)$. The robotic approach was associated with a higher incidence of delayed gastric emptying (26\% vs. $11 \%, \mathrm{P}=0.029)$, but a multivariate analysis showed that only older age (OR 1.03, P=0.012) and non-pancreatic cancer tumor type $(\mathrm{OR} 0.46, \mathrm{P}=0.014)$ predicted the occurrence of delayed gastric emptying. Multivariate analysis showed also that the robotic approach did not significantly mitigate for severe postoperative complications, but was the only factor protective against wound infection (OR $0.27, \mathrm{P}<0.0005)$ and was also protective against POPF (OR 0.33, P=0.019) (16).

$\mathrm{He}$ and coworkers reported the outcome of robotic pancreatectomies in 44 overweight patients (BMI $>25 \mathrm{~kg} / \mathrm{m}^{2}$ ) in the context of a 1:2 propensity score matched comparison with the open procedure. Overall, 127 patients with a median BMI of $29.9 \mathrm{~kg} / \mathrm{m}^{2}$ [interquantile range (IQR): 27.0-31.8] were included in this study. The two groups (44 vs. 83 patients) were matched based on age, gender, ASA classification, type of procedure, histopathology, history of neoadjuvant therapy, and BMI. Overall, there were 67 distal pancreatectomies, 50 pancreatoduodenectomies, and 10 total pancreatectomies. The robotic approach was associated with a lower median EBL [100 (IQR: 75-200) vs. 300 (IQR: 200-600) $\mathrm{mL} ; \mathrm{P}<0.001)$ and with a shorter mean length of hospital stay $(6.9 \pm 3.0$ vs. $9.2 \pm 5.6$ days; $\mathrm{P}=0.19)$. Patients receiving a robotic procedure did not require intraoperative transfusions of RBC, which were instead required in 5 patients in the open group (6\%). This difference was not statistically significant (17).

Sahakyan and coworkers reported on 402 distal pancreatectomies performed in normal weight patients $\left(\mathrm{n}=191\right.$; mean BMI: $\left.22.3 \pm 1.7 \mathrm{~kg} / \mathrm{m}^{2}\right)$, overweight patients $\left(\mathrm{n}=155\right.$; mean BMI: $\left.27.2 \pm 1.4 \mathrm{~kg} / \mathrm{m}^{2}\right)$, and obese patients $\left(\mathrm{n}=56\right.$; mean BMI: $\left.33.7 \pm 3.8 \mathrm{~kg} / \mathrm{m}^{2}\right)$. The three groups had similar baseline parameters, but hypertension $(39.3 \%$ vs. $27.1 \%$ vs. $19.4 \%, \mathrm{P}=0.008)$ and diabetes mellitus $(26.8 \%$ vs. $12.9 \%$ vs. $10.5 \%, \mathrm{P}=0.007)$ were more frequently observed in obese patients. Obese patients had longer median operative time [190 (IQR: 61-480) vs. 158 (IQR: 56-520) vs. 153 (IQR: 29-374) minutes; $\mathrm{P}=0.009]$ and median $\mathrm{EBL}$ [200 (IQR: 0-2,800) vs. 50 (IQR: 0-6,250) vs. 90 (IQR: $0-2,000) \mathrm{mL} ; \mathrm{P}=0.01]$. Obesity was also associated with more frequent occurrence of postoperative complications (30.9\% vs. $38.1 \%$ vs. $48.2 \%$; $\mathrm{P}=0.04$ ), but a similar rate of severe complications ( $16.8 \%$ vs. $22.6 \%$ vs. $21.4 \%$ ), and an increased incidence of POPF (27.2\% vs. $34.2 \%$ vs. $46.4 \%$; $\mathrm{P}=0.023$ ), but a similar rate of clinically relevant $\mathrm{POPF}$ ( $15.2 \%$ vs. $17.4 \%$ vs. $25.0 \%$ ). The rate of intraoperative unfavorable incidents was higher in obese patients $(7.9 \%$ vs. $13.5 \%$ vs. $23.2 \% ; \mathrm{P}=0.007)$, despite similar rates of conversion to open surgery (0.5\% vs. $3.2 \%$ vs. $1.8 \%)(18)$.

In conclusion, BMI is only a surrogate of body fatness that does not accurately define body composition. As 
such, it just captures the tip of the iceberg in the complex interplay that involves nutritional status, pancreatic cancer, and pancreatic resections. With this limitation, patients with high BMI do generally worse following pancreatic resections when compared to patients with normal body weight. Difference in outcome, however, is not so relevant as to justify restriction in access to pancreatic resections for obese patients and/or a selection based on BMI alone. Underweight, sarcopenia, and cachexia, on the other hand, are even worse nutritional conditions as compared to obesity. Patients facing these conditions should receive preoperative nutritional support and postoperative personalized nutrition. Studies using more sophisticated nutritional metrics are urgently needed to define the true impact of nutritional status of pancreatic resections performed for cancer and implement tailored therapeutic interventions. The impact of minimally invasive surgery also needs to be better defined. In general, a minimally invasive approach could be beneficial when there is a higher surgical risk, such as in obese patients. However, visceral obesity and fatty infiltration of the pancreas could make minimally invasive pancreatic resections more complex in obese patients. At least in theory, the robotic approach could reduce the impact of these technical hurdles.

\section{Acknowledgments}

Funding: None.

\section{Footnote}

Provenance and Peer Review: This article was commissioned by the editorial office, Hepatobiliary Surgery and Nutrition. The article did not undergo external peer review.

Conflicts of Interest: All authors have completed the ICMJE uniform disclosure form (available at http://dx.doi. org/10.21037/hbsn-20-498). All authors have no conflicts of interest to declare.

Ethical Statement: The authors are accountable for all aspects of the work in ensuring that questions related to the accuracy or integrity of any part of the work are appropriately investigated and resolved.

Open Access Statement: This is an Open Access article distributed in accordance with the Creative Commons Attribution-NonCommercial-NoDerivs 4.0 International
License (CC BY-NC-ND 4.0), which permits the noncommercial replication and distribution of the article with the strict proviso that no changes or edits are made and the original work is properly cited (including links to both the formal publication through the relevant DOI and the license). See: https://creativecommons.org/licenses/by-nc-nd/4.0/.

\section{References}

1. Gianotti L, Besselink MG, Sandini M, et al. Nutritional support and therapy in pancreatic surgery: A position paper of the International Study Group on Pancreatic Surgery (ISGPS). Surgery 2018;164:1035-48.

2. Lee SH, Chung MJ, Kim B, et al. The significance of the prognostic nutritional index for all stages of pancreatic cancer. Nutr Cancer 2017;69:512-9.

3. Gilliland TM, Villafane-Ferriol N, Shah KP, et al. Nutritional and metabolic derangements in pancreatic cancer and pancreatic resection. Nutrients 2017;9:E243.

4. Alwarawrah Y, Kiernan K, MacIver NJ. Changes in nutritional status impact immune cell metabolism and function. Front Immunol 2018;9:1055.

5. Hébuterne X, Lemarié E, Michallet M, et al. Prevalence of malnutrition and current use of nutrition support in patients with cancer. JPEN J Parenter Enteral Nutr 2014;38:196-204.

6. Seika P, Klein F, Pelzer U, et al. Influence of the body mass index on postoperative outcome and long-term survival after pancreatic resections in patients with underlying malignancy. HepatoBiliary Surg Nutr 2019;8:201-10.

7. Sánchez-Velázquez P, Muller X, Malleo G, et al. Benchmarks in pancreatic surgery: a novel tool for unbiased outcome comparisons. Ann Surg 2019;270:211-8.

8. World Health Organization. Obesity and overweight. Available online: http://www.who.int/ mediacentre/ factsheets/fs311/en/. Accessed May 15, 2020.

9. Pausch T, Hartwig W, Hinz U, et al. Cachexia but not obesity worsens the postoperative outcome after pancreatoduodenectomy in pancreatic cancer. Surgery 2012;152:S81-8.

10. Selassie M, Sinha AC. The epidemiology and aetiology of obesity: A global challenge. Best Pract Res Clin Anaesthesiol 2011;25:1-9.

11. Vecchié A, Dallegri F, Carbone F, et al. Obesity phenotypes and their paradoxical association with cardiovascular diseases. Eur J Intern Med 2018;48:6-17.

12. Rosso E, Casnedi S, Pessaux P, et al. The role of "fatty pancreas" and of BMI in the occurrence of pancreatic 
fistula after pancreaticoduodenectomy J Gastrointest Surg 2009;13:1845-51.

13. Chooi YC, Ding C, Magkos F. The epidemiology of obesity. Metabolism 2019;92:6-10.

14. Rahib L, Smith BD, Aizenberg R, et al. Projecting cancer incidence and deaths to 2030: the unexpected burden of thyroid, liver, and pancreas cancers in the United States. Cancer Res 2014;74:2913-21.

15. Renehan AG, Tyson M, Egger M, et al. Body- mass index and incidence of cancer: a systematic review and metaanalysis of prospective observational studies. Lancet. 2008;371:569-78.

Cite this article as: Perrone VG, Iacopi S, Amorese G, Boggi U. Impact of nutritional status on outcome of pancreatic resections for pancreatic cancer and periampullary tumors. HepatoBiliary Surg Nutr 2020;9(5):669-672. doi: 10.21037/hbsn-20-498
16. Girgis MD, Zenati MS, Steve J, et al. Robotic approach mitigates perioperative morbidity in obese patients following pancreaticoduodenectomy. HPB (Oxford) 2017;19:93-8.

17. He S, Ding D, Wright MJ, et al. The impact of high body mass index on patients undergoing robotic pancreatectomy: A propensity matched analysis. Surgery 2020;167:556-9.

18. Sahakyan MA, Røsok BI, Kazaryan AM, et al. Impact of obesity on surgical outcomes of laparoscopic distal pancreatectomy: A Norwegian single-center study. Surgery 2016;160:1271-8. 